\title{
Ideologías lingüísticas y la representación del colectivo LGTBI en las Columnas sobre la lengua (CSL)
}

\section{Linguistic ideologies and the representation of the LGTBI community in Columns about language}

Laura Melero Carnero

Universitat d'Alacant, Alicante

lmc71@alu.ua.es

ACCESO ABIERTO / OPEN ACCESS

Cita: Melero Carnero, Laura (2021). Ideologías lingüísticas y la representación del colectivo LGTBI en las Columnas sobre la lengua. Textos en Proceso, 7(2), pp. 1-23. https://doi.org/10.17710/tep.2021.7. 2.1melero

Editoras: Esperanza Alcaide Lara (Universidad de Sevilla) y Ana Pano Alamán (Università di Bologna)

Recibido: 07/10/2021

Aceptado: 15/12/2021

Conflicto de intereses: La autora ha declarado que no posee conflicto de intereses.

Copyright: @ Laura Melero Carnero. Esta obra está bajo licencia $\underline{\text { Creative }}$ Commons Reconocimiento 4.0.

\section{Resumen}

A través del concepto de las ideologías lingüisticas como marco teórico y de los estudios enmarcados dentro de la lingüistica queer, el presente artículo analiza los discursos expresados en las Columnas sobre la lengua sobre el colectivo LGTBI. El principal objetivo de este artículo es averiguar si los columnistas seleccionados en nuestro corpus están a favor o en contra de apoyar al colectivo LGTBI mediante el uso de ciertos términos lingüísticos y qué posiciones toman ante los términos que discriminan a todo el movimiento. Para ello, se ha elaborado un corpus que incluye la información sobre los autores y las autoras que han hablado sobre el movimiento queer, así como las columnas que se han escrito sobre este tema publicadas entre 2002 y 2021. Los resultados que arrojan nuestro análisis demuestran que existe un choque entre los estudios queer y las ideologías lingüísticas de los columnistas, quienes, a pesar de mostrar su apoyo al movimiento, algunos todavía muestran resistencia a aceptar nuevos términos inclusivos por no dañar el estatus de la lengua española.

Palabras clave: columna sobre la lengua, ideologías sobre la lengua, lingüística queer.

\footnotetext{
Abstract

By the concept of linguistic ideologies as a theoretical framework and the studies belonging to the queer linguistics, the present article analyses the discourses towards the LGTBI group, expressed on the columns on language. The main
} 
objective of this article is to find out if the chosen columnists in our corpus are in favour or against the LGTBI movement in linguistic terms and what positions do they take in light of these terms that discriminate the whole movement. Therefore, a corpus including the information about the columnists who wrote about the queer movement has been elaborated, together with the columns talking about this topic, published between 2002 and 2021. The results that our analysis has produced show that there is a collision between queer studies and the columnists' linguistic ideologies, showing that despite the columnists' support towards the movement, some of them show a resistance to accept new inclusive terms in order to not damage the status of the Spanish language.

Keywords: columns of language, language ideologies, queer theory.

\section{Introducción}

Desde que los estudios queer irrumpieron en la sociedades americanas, latinoamericanas y españolas entre los años 80 y 90, se han ido desarrollando ensayos y trabajos de investigación con el fin de entender las cuestiones y problemáticas generadas dentro del colectivo LGTBI. Entre las áreas de conocimiento a las que se han aplicado están la educación, especialmente la enseñanza de idiomas, la lingüística, la sociología, el derecho o la salud, entre otras. En los últimos años se han empezado a investigar en el área de los medios de comunicación, especialmente en la prensa española, los discursos de representación de las personas LGTBI. Los estudios queer también están creciendo dentro del mundo del hispanismo, con artículos, Trabajos de Fin de Grado, Trabajos de Fin de Máster o Tesis Doctorales que se han fijado en la cuestión queer ${ }^{1}$. A partir de la teoría de las ideologías lingüísticas de Woolard (1992) y del Valle (2016), y de los estudios sobre las Columnas sobre la lengua (CSL), junto con la Lingüística queer como eje del marco teórico, el presente artículo quiere aproximarse a la representación del colectivo queer en este tipo de texto periodístico. Esta investigación se plantea las siguientes preguntas: ¿cómo reflejan los autores sus ideologías lingüísticas en sus columnas? ¿Cuáles son las opiniones que tienen los columnistas con respecto a los términos inclusivos que defiende el colectivo queer? ¿Existe alguna división de opiniones entre los columnistas con estos términos queer? Las respuestas a estas preguntas son el objetivo fundamental de este trabajo, que consiste en analizar las ideologías lingüísticas reflejadas en las CSL sobre el tema LGTBI. Para ello, se ha creado un corpus de CSL de temática LGTBI recopiladas a partir de la base de datos de Columnas sobre la lengua METAPRES $\mathrm{y}$, de esta manera, averiguar si los columnistas seleccionados muestran o no su apoyo a las personas LGTBI y si se posicionan ante aquellos términos y expresiones peyorativos que discriminan al movimiento. Además, la hipótesis de la que se parte es que no todos los columnistas aceptan por igual los nuevos términos propuestos

\footnotetext{
1 Algunos de los estudios son los de de Lauretis (2015), Oller y Chavero (2016), Solana (2018), Theodoro y Bailén (2018), Navarro-Carrascosa (2019), Córdova (2019), Guijarro-Ojeda y RuizCecilia (2019), Carratalá y Herrero-Jiménez (2019), Cazorla (2019) y Marín-Calderón (2020).
} 
debido a su purismo lingüístico, mientras que otros proponen alternativas que se ajusten a la lengua española y que estén recogidas por el Diccionario.

\section{Marco teórico}

\subsection{Las ideología de la lengua: de los primeros estudios a la actualidad}

Una de las investigadoras pioneras en el estudio de las ideologías lingüísticas, Kathryn Woolard (1992) planteaba la siguiente pregunta: si el término ideología ha generado mucha confusión a la hora de definirla, ¿por qué se ha elegido como concepto "paraguas"? La respuesta según ella es porque la noción ha recibido una gran atención en los últimos años en los estudios del lenguaje (Woolard, 1992, p. 236). Woolard (1992), basándose en ensayos y reseñas alrededor del debate de las ideologías, resume sus características definitorias en cuatro puntos: a) la ideología suele ser tomada como "conceptual o ideacional", es decir, que tiene que ver con "la conciencia, las creencias, las nociones o las ideas"; b) el origen de la ideología reside en "los intereses de una determinada posición social"; c) la ideología acoge una noción mucho más central: la distorsión o falsedad; y d) se atribuye a la ideología "una conexión íntima con el poder social y su legitimación" (Woolard, 1992, pp. 237-238).

Kroskrity (2010), siguiendo a Woolard, las define como un "conjunto de creencias y concepciones acerca del lenguaje, planteados de manera explícita o manifestados en prácticas comunicativas, que sirven a una comunidad para racionalizar el uso lingüístico y que a menudo responden a sus intereses políticos y económicos, sea los de la totalidad de sus miembros o los de grupos sociales determinados." (Citado en: Rojas, 2013, p. 87). Dos categorías centrales para el estudio de las ideologías lingüísticas son ideologemas y nacionalismo lingüístico. Para Molina (2019), la categoría de "ideologemas" son "máximas que funcionan como presupuestos del discurso", que se pueden encontrar en diferentes épocas, instituciones o campos discursivos, y que se establecen cuando logra ser aceptado por la sociedad (Molina, 2019, p. 4). Geeraerts (2008) incluye la categoría "nacionalismo lingüístico" (discursos políticos), que consiste en "la selección de una variedad como estándar", cuya función es tanto para "garantizar la participación de todos los ciudadanos de una nación como para definir la naturaleza de su sociedad" (Geeraerts, 2008, pp. 56-59, citado en: Frühbeck Moreno, 2017, p. 3). Este segundo concepto es un fenómeno común en la mayoría de las columnas sobre la lengua, puesto que los columnistas critican la incorporación de anglicismos en la lengua española, independientemente de su popularidad en la comunidad de hablantes, e invitan a sus lectores a que utilicen alternativas más cercanas al español. Otros autores como Del Valle (2016) o Swiggers (2019) incluyen nuevas conceptualizaciones como tipos de ideologías lingüísticas, "macroplanos" (Swiggers, 2019) o "espacios discursivos" (Del Valle, 2016). Según Del Valle (2016), el lenguaje "se tematiza en múltiples espacios discursivos" (Del Valle, 2016, p. 629): a) "en la praxis lingüística" (cuando se adoptan ciertos patrones para utilizar un habla cuidado); b) en la reproducción de formas relacionadas con determinadas identidades sociales (cómicos o anuncios que imitan "estereotipos sociolingüísticos"); c) en las discusiones que se hacen en público acerca de la 
corrección del lenguaje (carta a un director donde el lector se queja de los usos de los periodistas); d) en textos que "definen objetos lingüísticos" (manuales de gramática, diccionarios); y e) en textos donde "se regula jurídica y políticamente la distribución social de las lenguas" (leyes que establecen oficialidad o cooficialidad de las lenguas habladas en un país) (Del Valle, 2019, p. 629). Los espacios discursivos en los que se encuentran las Columnas sobre la lengua son el de la "praxis lingüística" y el que tiene que ver con las "discusiones que se hacen en público acerca de la corrección del lenguaje". Sobre la praxis lingüística, los columnistas sobre la lengua se apoyan de los documentos de instituciones oficiales como la Real Academia Española para explicar a sus lectores el error de ciertas palabras o expresiones en la lengua española. En cuanto a lo "público", se hace evidente en autores como Amando de Miguel, que reciben cartas de lectores donde expresan sus quejas por el uso de expresiones inadecuadas en las columnas y, con ellas, el columnista responde a su lector públicamente mediante la publicación de una columna en un medio accesible para todo el mundo, tal y como se verá en el análisis del presente trabajo.

\subsection{Teoría queer}

\subsubsection{Primeros estudios}

En los años ochenta, Sedgwick (1985) fue la primera investigadora en hablar sobre el término "homosexual", pero lo hizo con la palabra homosocial para "describir los lazos sociales entre personas del mismo sexo" (Sedwigck, 1985, p. 1). Posteriormente, en los años 90, Wittig (1992) adopta un enfoque político y filosófico, denominado "lesbianismo materialista", para tratar la heterosexualidad no como una "institución", sino como un "régimen político que se basa en la sumisión y la apropiación de las mujeres" y que, para acabar con este régimen, se deben "destruir política, filosófica y simbólicamente las categorías 'hombres' y "mujeres"' (Wittig, 1992, p. 15). Para Butler (2006), la teoría queer suele confundirse con la idea de oposición a cualquier reivindicación de identidad. En su opinión, la teoría queer no se opone a la asignación de género o los deseos de aquellas personas que quieren ser designadas con una identidad (Butler, 2006, p. 22). Precisamente la tarea de todos los movimientos queer es "distinguir entre las normas y convenciones que permiten a la gente respirar, desear, amar y vivir, y aquellas normas y convenciones que restringen o coartan las condiciones de vida" (Butler, 2006, p. 23).

En el caso de España, destacan los ensayos Paul B. Preciado $(2002,2009)$ o Javier Sáez (2003). Preciado (2002) introduce el término de "contrasexualidad", un sistema originario de Foucault que la define como la "teoría del cuerpo que se sitúa fuera de las oposiciones hombre/mujer, masculino/femenino, heterosexualidad/ homosexualidad" y cuyo objetivo es "el estudio de las transformaciones tecnológicas de los cuerpos sexuados y generizados" (Preciado, 2002, pp. 14-16). Según Preciado, esta teoría "no rechaza la hipótesis de las construcciones sociales o psicológicas del género, pero las resitúa como mecanismos, estrategias y usos en un sistema tecnológico más amplio" (p. 16). En otro ensayo Preciado (2009) hace historia del término "queer": en el s. XVIII en el inglés, queer se utilizaba para nombrar algo "inútil", "mal hecho", "falso" o "excéntrico" y que "ponía en cuestión 
el buen funcionamiento del juego social" (Preciado, 2009, p. 14). Se utilizaba para hablar de "todo aquel que por su peculiaridad o por su extrañeza no pudiera ser inmediatamente reconocido como "hombre o mujer"” (Preciado, 2009, p. 14). No obstante, activistas de grupos como Act Up, Radical Furies o Lesbian Avengers le dieron la vuelta al significado "queer" y lo convirtieron en un adjetivo reivindicativo para la crítica social y la intervención cultural (Preciado, 2009, pp. 14-15). Preciado lo define como un "movimiento post-identitario", puesto que se trata de "una posición de crítica atenta a los procesos de exclusión y de marginalización que genera toda ficción identitaria". Se trata de un movimiento de "disidentes de género y sexuales que resisten frente a las normas que impone la sociedad heterosexual dominante" (Preciado, p. 16). Por último, Sáez (2003) sostiene que la década de los setenta y ochenta supone la aparición de los primeros estudios pioneros sobre "homosexualidad" con perspectiva reivindicativa. No obstante, es en la década de los noventa cuando aparecen los primeros ensayistas gais "que toman la palabra desde diferentes perspectivas" (Sáez, 2003, p. 20). Durante la década de los ochenta y noventa, en España empiezan campañas mediáticas contra el colectivo LGTBI: el uso de la pandemia del sida de los años ochenta por parte de los grupos políticos conservadores o el lanzamiento de calificativos como "el lobby gay" o "la mafia rosa" para crear una "imagen amenazante" del colectivo (Sáez, 2003, p. 21). Con el surgimiento de estos primeros ensayos, los estudios queer hacen una crítica al sistema heterocentrado de sexo y género con criterios como la raza, clase social o discapacidad (Sáez, 2003, pp. 22-23).

\subsubsection{Lingüística queer}

La Lingüistica queer (LQ) comienza a finales del siglo XX con el trabajo de Livia y Hall titulado Queerly Phrased Language, Gender and Sexuality (1997), trabajo que recopila ensayos dedicados al estudio de la teoría queer desde una perspectiva lingüística, como el estudio del discurso o lenguaje lésbico, del discurso sobre gays y lesbianas, del lenguaje homofóbico, la identidad liminal, la performatividad o la subjetividad de género, entre otros. A raíz de este trabajo, otros estudiosos (Barrett, 2002; Borba, 2015; Leap y Boellstorf, 2004; Borba y Ostermann, 2008; Bucholtz y Hall, 2004; y Motschenbacher y Stegu, 2013) empezaron a definir la Lingüística queer: Barrett (2002) la define como "the study of language augmented with ideas from queer theory" (Barrett, 2002, p.26). La lingüística queer se caracteriza por el hecho de que, según Bucholtz y Hall (2004),no sólo se limita al estudio de una sola orientación, sino que tiene en cuenta todas las "identidades, ideologías y prácticas sexualizadas que pueden surgir en contextos socioculturales específicos" (Bucholtz y Hall, 2004, p.490). Para Borba (2015), la lingüística queer analiza "cómo los individuos considerados no normativos negocian sus identidades dentro de las limitaciones discursivas de la heteronormatividad repitiéndola o subvirtiéndola a través de sus interpretaciones lingüísticas" (Borba, 2015, p. 9). Para Leap y Boellstorf (2004) las dos preocupaciones importantes en su colección de ensayos son la incorporación de las "formas de hablar sobre los deseos, las prácticas y las subjetividades" de las personas LGTBI a los "intercambios transnacionales", y cómo estas se ven "afectadas por estas relaciones" (Leap y Boellstorf, 2004, p. 2). Ambos autores no hablan sobre el término "lingüística queer", sino que hablan del término gay men's English, concepto que utilizan algunos autores del volumen para 
referirse a un movimiento originado en Estados Unidos que consiste en la "circulación global de hombres homosexuales" (Leap y Boellstorf, 2004, p. 2). Además, hablar de este término implica tres puntos fundamentales: "llama la atención sobre las tensiones entre las formas de hablar sobre el deseo del mismo sexo", que están vinculadas tanto "a las experiencias de los hombres homosexuales" como a "las identidades y experiencias de las mujeres identificadas con el mismo sexo"; que se pregunta sobre "la adaptabilidad" del lenguaje de los hombres homosexuales "al mundo lingüístico de las mujeres"; y cómo el concepto determina "qué hombres (y, en algunos entornos, qué mujeres) proporcionan los modelos autorizados para estos códigos que circulan globalmente" (Leap y Boellstorf, 2004, pp. 2-3). Para Motschenbacher y Stegu (2013), "la lingüística queer ha evolucionado dentro de los estudios de lenguaje y género" de tal manera que ambos estudios han logrado mantenerse entrelazados (Motschenbacher y Stegu, 2013, p. 521). En esta disciplina, según estos dos autores, los lingüistas queer se cuestionan varios puntos dentro de la dicotomía masculino-femenino y mencionan dos aspectos: en primer lugar, que "todas las categorías de identidad son problemáticas" porque dejan fuera a las personas que no se sienten identificadas con los "requisitos normativos" (Motschenbacher y Stegu, 2013, p. 523). Sin embargo, a pesar de que uno de los objetivos de la lingüística queer es "deconstruir la heteronormatividad", los dos autores defienden que es difícil "encontrar un contexto que esté completamente libre de influencias heteronormativas, incluso si la mayoría o todos los participantes se autoidentifican como no heterosexuales" (Motschenbacher y Stegu, 2013, p. 524).

En España, como ya se ha mencionado en la introducción, el tema de la lingüística queer está empezando a tener auge con artículos, trabajos de fin de máster como o tesis doctorales el de Navarro-Carrascosa (2020a), NavarroCarrascosa (2020b), o Moreno Sánchez (2018). Navarro-Carrascosa (2020a), en su artículo, se encarga de caracterizar los rasgos lingüísticos del habla de la comunidad LGTBI a través de dos conversaciones coloquiales realizadas en Madrid y Valencia. Por otra parte, en su tesis doctoral, Navarro-Carrascosa (2020b) analiza el papel que tienen las formas nominales de tratamiento o FNT en el habla LGTBI a través de entrevistas, conversaciones coloquiales y publicaciones en las plataformas de Twitter, Whatsapp y Facebook (Navarro-Carrascosa, 2020b, pp. 29-30). Por último, similar a este autor, Moreno Sánchez (2018), en su tesis doctoral, analizó el discurso de la legislación educativa en España (LOE-LOMCE) desde una perspectiva queer, con el propósito de "identificar elementos de heteronormatividad" y buscar alternativas a esta en el ámbito educativo desde los puntos de vistas del "Análisis Crítico del Discurso y los planteamientos de la teoría queer" (Moreno Sánchez, 2018, p. 46).

\subsubsection{Representación del colectivo LGTBI en la prensa española}

Como señalamos en la introducción, a pesar de que los estudios del colectivo LGTBI han abundado en otras áreas de investigación como la educación, en la cultura, en la televisión o en la literatura, los estudios de lingüística desde la perspectiva LGTBI están en auge, como se ha podido ver con los trabajos de Navarro-Carrascosa. Sobre el estudio de la representación del colectivo LGTBI en la prensa, Theodoro y Bailén (2018) sostienen que tanto el término "representación 
mediática" como el de "visibilidad" guardan un vínculo con el ámbito de la esfera pública (Theodoro y Bailén, 2018, p. 51). No obstante, algunos medios visibilizan ciertos hechos según sus intereses u objetivos, o incluso promueven discursos discriminatorios, es decir, que "cuanto más represivo es el contexto sociocultural en el que se encuentra el medio, mayor es el riesgo de silenciamiento" (Theodoro y Bailén, 2018, p. 51). En este punto, cabe destacar la diferencia de términos que hacen los autores entre "visualidad" (ser visto mediante imágenes) y "visibilidad" (proporcionar relevancia social a determinadas imágenes) (Theodoro y Bailén, 2018, p. 52). Ambos autores sostienen que, aunque estas imágenes están "omnipresentes" en la sociedad, "no todas ellas adquieren un status de visibile" (Theodoro y Bailén, 2018, p. 52). En el caso de España, según Carratalá y HerreroJiménez (2019), desde 2015, si un medio de comunicación comete un delito de odio y su mensaje alcanza a un gran número de personas, las penas son mayores (Carratalá y Herrero-Jiménez, 2019, p. 63). No obstante, al no existir una "legislación estatal que proteja a las personas LGTBI de toda discriminación", esto ha llevado a crear "iniciativas legislativas autonómicas" con el objetivo de luchar contra los discursos de odio (Carratalá y Herrero-Jiménez, 2019, p.67). Ambas autoras afirman que "estas leyes sitúan a los medios de comunicación como actores clave cuya regulación es esencial para alcanzar el principio de igualdad" (Carratalá y Herrero-Jiménez, 2019, p. 67).

Sobre el tratamiento del matrimonio igualitario, cada periódico español tiene sus líneas ideológicas: por un lado, los periódicos conservadores suelen difundir su postura contraria a estos matrimonios, mientras que los periódicos progresistas muestran con sus discursos su apoyo al colectivo LGTBI+ (Guijarro-Ojeda, 2015, apud Guijarro-Ojeda y Ruiz-Cecilia, 2019, p. 7). No obstante, a pesar de que el estudio de la representación del colectivo LGTBI está empezando a tener auge, no todas las orientaciones del colectivo se representan de igual modo en todos los medios de comunicación. Esto último lo refleja Oliveira (2019) en su estudio sobre la representación mediática de la transexualidad: en él, el autor sostiene que hay diferencias entre la "prensa generalista" y los "medios nativos digitales" (Oliveira, 2019, p.150). En los resultados obtenidos, Oliveira sostiene que los medios nativos digitales presentan "un enfoque más diverso y completo", que siguen las recomendaciones de las asociaciones en cuanto a la información sobre la transexualidad y que divulgan "una imagen más positiva" y "una postura más combativa y reivindicativa" que los medios generalistas (Oliveira, 2019, pp. 162$63)$.

Cazorla (2019) analiza en su trabajo la presencia de la "identidad gay" en las columnas periodísticas de Elvira Lindo, autora cuyos escritos se muestran a favor de los derechos del colectivo LGTBI (Cazorla, 2019, p. 42). Una de las cuestiones que se pone en evidencia en los textos de la autora es "la creación de una marca gay" que surge de una "práctica perversa" realizada a través de los medios de comunicación, "que se alimenta de la hipocresía del espectador considerado progresista y de mentalidad abierta, pero que consume este tipo de productos televisivos, al igual que del espectador que finge escandalizarse con todo aquello que esté relacionado con el mundo homosexual pero que es incapaz de despegarse del televisor." (Cazorla, 2019, p. 51). Finalmente, Oller y Chavero (2016), en su 
estudio sobre la representación del colectivo LGTBI en Ecuador revelaron que el colectivo está representado con imágenes que responden a estas características:

1) caricaturización del tema y de las personas LGTBI; 2) representación del colectivo LGTBI como un grupo homogéneo, obviando que en su interior conviven personas con diferentes identidades, orientaciones sexuales, problemas y necesidades $41 ; 3$ ) invisibilización; 4) exclusión o conversión del colectivo en un "ellos"; 5) victimización; 6) exotización; 7) sensacionalismo y morbo; 8) estereotipización negativa, asociada con frecuencia a formas punitivas, de manera que se presenta todo lo no heterosexual como algo no solo negativo, sino peligroso y merecedor de sanción; 9) tratamiento diferenciado por parte de los medios de comunicación convencionales y las redes sociales y 10) diferenciación en el trato que ofrecen los grandes medios nacionales y las dinámicas de funcionamiento de los medios de comunicación de provincias, mucho más accesibles estos últimos y con los que mantienen un trato más cordial e incluso amigable. (Chavero, Oller y Troya, 2016, apud Oller y Chavero, 2016, pp. 45-46).

\subsection{Las Columnas sobre la lengua (CSL): un tipo de texto para expresar las ideologías lingüísticas}

\subsubsection{Orígenes de las CSL}

Las columnas sobre la lengua (o conocidas en francés como croniques de langage) se definen como el "conjunto de artículos (o posts) dedicados al idioma, producidos por la persona y publicados de forma regular, con mayor frecuencia en la prensa escrita" (Remysen, 2005, p. 271-272). La chronique de langage se caracteriza por ser un discurso metalingüistico, es decir, que se trata de un discurso que habla sobre la lengua; por tener un carácter epilingüístico, porque presenta "juicios de valor" que están relacionados con los usos de la lengua; por poseer un carácter pedagógico, puesto que hace reflexionar a sus lectores sobre su propia lengua; y por tener un carácter divulgador (Remysen, 2005, pp. 272-273). Por otra parte, estas crónicas siguen una tipología que las hace diferenciarse de otro tipo de texto periodístico según Remysen (2005): la formación y los antecedentes del columnista (influye en la visión que estos tienen sobre la lengua), periodo de publicación, (cada columna representa las preocupaciones de la época en cuanto a la lengua), canal de difusión (se publican principalmente en periódicos y revistas, o incluso en colecciones), público (depende del medio donde se publique la crónica), contenido (la mayor parte tiene que ver con el léxico y comprende los problemas de semántica lexical); forma (cada crónica posee una estructura particular) y la información sobre la norma (los columnistas pueden dar un enfoque prescriptivo o descriptivo en mayor o menor medida) (Remysen, 2005, pp. 273-276). En España, la primera vez que aparecieron estos textos periodísticos fue con Fe de erratas, publicado en 1883 por Antonio de Valbuena (con el seudónimo de Miguel Escalada) en El Imparcial (Serrano Serrano, 2008, citado en: Marimón, 2019b, p. 8). No obstante, tras la Guerra Civil Española, Julio Casares fue el primer columnista sobre la lengua en retomar esta actividad periodística con su serie Cosas del lenguaje en 1939 en el diario ABC. Este columnista, junto con Eustaquio Echauri, Manuel Rabanal y Ramón Carnicer, "abren paso a los columnistas que, durante el resto del siglo XX, y hasta hoy continúan cultivando el género" (Marimón, 2019b, p. 8). En cuanto al área de estudios de lingüística española, el grupo de Investigación METAPRES- 
$\mathrm{COLING}^{2}$ se ha encargado de caracterizar estas columnas periodísticas en la prensa española desde 2016 hasta la actualidad y analizar las características de cada uno de los columnistas españoles y sus trabajos escritos desde los años 40 (década en la cual se inició esta actividad periodística) hasta el año actual.

\subsubsection{Las ideologías de las lenguas en las CSL}

Pano Alamán (2019) define los discursos de las Columnas sobre la lengua como "un tipo de discurso pedagógico que lleva a los lectores a reflexionar sobre la lengua y que suele ocuparse de aspectos léxico-semánticos, sin excluir las cuestiones de morfosintaxis" (2019b, p. 341). Los columnistas, cuando ven un uso erróneo, marcan dicho uso entre comillas o en cursivas para mostrar a sus lectores su uso inadecuado "en función de su ideología lingüística" (Pano Alamán, 2020, p. 142), y toman como referencia para sus argumentos la norma prescrita por los trabajos de la Real Academia Española, para "favorecer el buen uso, entendido como uso compartido, de la lengua española entre todos los hablantes" (Martínez Egido, 2019, p. 177). Para Guerrero Salazar (2019), los columnistas sobre la lengua "son actores sociales implicados en el discurso", quienes, además de usar "sus experiencias y estrategias individuales", se apoyan en "representaciones sociales" y las afianza en sus escritos (2019b, p. 187). Tanto Sánchez Manzanares (2019) como Santamaría (2019) coinciden en que los columnistas reproducen sus ideologías lingüísticas ante la introducción de los neologismos y préstamos de otros idiomas, como son los anglicismos. En este sentido se observan dos fenómenos: por un lado, la llamada "ideología del nacionalismo lingüístico" (concepto que ya se ha visto en el primer subapartado de las bases teóricas), puesto que los autores promueven "las ideas sobre la preservación y defensa de la unidad de la lengua mediante proposiciones historicistas sobre la tradición del español" (2019, p. 232); y, por otro lado, el llamado "purismo léxico", fenómeno que muestra "resistencia ante lo nuevo y el cambio", es decir, ante la llegada de préstamos y neologismos, puesto que estos son considerados como "un ataque al orden establecido, a la norma" y que "debe ser rechazado" (Santamaría, 2019, p. 237).

\section{El corpus}

Para el presente trabajo se ha creado un corpus de 22 columnas sobre la lengua escritas entre los años 2002 y 2021 que tratan sobre cuestiones lingüísticas relacionados con el tema LGTBI. Estos años establecidos para la creación de nuestro corpus nos permiten comprobar cómo se observaba veinte años atrás al colectivo LGTBI y cómo en la actualidad se opina de dicho colectivo. El corpus, además, se compone de seis columnistas de cinco periódicos españoles distintos (cuatro de carácter nacional y uno de carácter regional). El motivo por el cual se han escogido estos columnistas es que, dentro del listado de columnistas recopilados en la base de datos METAPRES, estos son los que escriben a día de hoy con más frecuencia en los medios de comunicación escritos y cuyas columnas han prestado

\footnotetext{
2 Proyecto I+D+i PID2019-107265GB-100 "El columnismo lingüístico en la prensa española desde sus orígenes. Análisis multidimensional, caracterización y aplicaciones (METAPRES_COLING)" (2020-2023), cuyo objetivo principal es el estudio del columnismo lingüístico en la prensa española desde las perspectivas pragmático-discursiva, léxica y semiótica, y social del texto.
} 
atención a la cuestión LGTBI desde el punto de vista lingüístico. Aunque uno de ellos (Fernando Lázaro Carreter) ya no ejerce como columnista sobre la lengua, uno de sus artículos está dedicado al tema LGTBI. En la Tabla 1, se muestra información sobre los columnistas sobre la lengua, así como de sus trabajos, los años de inicio y fin de publicaciones de artículos, así como los medios escritos donde se publican dichos artículos. Las Tablas 2, 3, 4, 5, 6 y 7 contienen información acerca de los columnistas y sus trabajos (tal y como se ve en la Tabla 1), y además, se añade el número de CSL sobre la cuestión LGTBI que aparecen en sus trabajos (que se han seleccionado para este artículo) y el título de estas.

Tabla 1. Información sobre los columnistas seleccionados

\begin{tabular}{|c|c|c|c|c|}
\hline Nombre & Trabajo & Fecha inicio & Fecha fin & Periódico \\
\hline Fernando Lázaro Carreter & El nuevo dardo de la palabra & 1999 & 2002 & El País \\
\hline Álex Grijelmo & La punta de la lengua & 2013 & actualidad & El País \\
\hline Amando de Miguel & Errores y erratas & 2002 & 2005 & Libertad Digital \\
\hline Amando de Miguel & La lengua viva & 2005 & 2014 & Libertad Digital \\
\hline Amando de Miguel & Sin nombre & 2014 & actualidad & Libertad Digital \\
\hline Elena Álvarez Mellado & Sin nombre & 2017 & 2018 & Eldiario.es \\
\hline Lola Pons & Lengua & 2017 & actualidad & Verne (El País) \\
\hline Francisco Ríos Álvarez & La mirada de la lengua & 2002 & actualidad & La Voz de Galicia \\
\hline
\end{tabular}

Tabla 2. Información sobre Fernando Lázaro Carreter

\begin{tabular}{|ll|}
\hline Autor & Fernando Lázaro Carreter \\
\hline Nombre trabajo & El nuevo dardo de la palabra \\
\hline Número de artículos LGTBI & 1 \\
\hline Nombre de los artículos & Con algún género de dudas $(03 / 03 / 2002)$ \\
\hline
\end{tabular}

Tabla 3. Información sobre Álex Grijelmo

\begin{tabular}{|ll|}
\hline Autor & Álex Grijelmo \\
\hline Nombre trabajo & La punta de la lengua \\
\hline Número de artículos LGTBI & 5 \\
\hline Nombre de los artículos & 1. Homofobia: Como decimos gay $(19 / 06 / 2016)$ \\
& 2. El neologismo de Joan Monleon $(26 / 06 / 2018)$ \\
& 3. La mariconez de Mecano $(21 / 10 / 2018)$ \\
& 4. El revoltijo LGTBIfobia $(26 / 03 / 2017)$ \\
& 5. Matrimonios de hombres, patrimonios de mujeres \\
& $(09 / 11 / 2014)$ \\
\hline
\end{tabular}

Tabla 4. Información sobre Amando de Miguel

\begin{tabular}{|ll|}
\hline Autor & Amando de Miguel \\
\hline Nombre trabajo & $\begin{array}{l}\text { Errores y erratas } \\
\text { La lengua viva } \\
\text { Sin nombre }\end{array}$ \\
\hline Número de artículos LGTBI & 11 \\
\hline Nombre de los artículos & $\begin{array}{l}\text { 1. Homenaje a la minoría de los gayos }(08 / 07 / 2020) \\
\text { 2. Padre y madre, palabras vitandas }(23 / 06 / 2017)\end{array}$ \\
\hline
\end{tabular}


3. Sobre maricones y otras lindezas (i) $(12 / 09 / 2005)$

4. Sobre maricones y otras lindezas (II) $(13 / 09 / 2005)$

5 . Gayos y gallos $(05 / 10 / 2005)$

6. Hablemos de sexo $(12 / 08 / 2005)$

7. El pensamiento arco iris $(16 / 11 / 2016)$

8. Eterno sexo $(29 / 08 / 2005)$

9. Sobre sexo, género y sexualidad (28/07/2005)

10. Más sexo (23/09/2005)

11. La contienda de los sexos $(09 / 07 / 2021)$

Tabla 5. Información sobre Elena Álvarez Mellado

\begin{tabular}{|ll|}
\hline Autor & Elena Álvarez Mellado \\
\hline Nombre trabajo & Sin nombre \\
\hline Número de artículos LGTBI & 2 \\
\hline Nombre de los artículos & $\begin{array}{l}\text { 1. Todas, tod } @ \text { s, }, \text { todxs, todes: historia de la disidencia } \\
\text { gramatical }(27 / 06 / 2017) \\
\text { 2. Teoría marica o el insulto como bandera }(27 / 03 / 2017)\end{array}$ \\
\hline
\end{tabular}

Tabla 6. Información sobre Lola Pons

\begin{tabular}{|ll|}
\hline Autor & Lola Pons \\
\hline Nombre trabajo & Lengua \\
\hline Número de artículos LGTBI & 2 \\
\hline Nombre de los artículos & $\begin{array}{l}\text { 1. Lesbianismo: cuando el armario se abrió, estaba lleno } \\
\text { de palabras }(04 / 07 / 2018)\end{array}$ \\
& $\begin{array}{l}\text { 2. Masculinas, femeninas y viceversa: palabras con } \\
\text { identidad transgénero }(14 / 08 / 2017)\end{array}$ \\
\hline
\end{tabular}

Tabla 7. Información sobre Francisco Ríos Álvarez

\begin{tabular}{|ll|}
\hline Autor & Francisco Ríos Álvarez \\
\hline Nombre trabajo & La mirada de la lengua \\
\hline Número de artículos LGTBI & 4 \\
\hline Nombre de los artículos & 1. Elegetebefobia $(14 / 04 / 2017)$ \\
& 2. Periplo lexicográfico del homosexual $(03 / 07 / 2010)$ \\
& 3. No son gays (08/07/2002) \\
& 4. El despectivo "maricón" $(17 / 07 / 2021)$ \\
\hline
\end{tabular}

En el siguiente apartado, a partir del análisis de las CSL seleccionadas, se examinan cada uno de los artículos con temática LGTBI que han escrito los seis autores seleccionados del corpus. El apartado 4 está dividido en seis subapartados con cada uno de los autores y contiene ejemplos de sus artículos, a partir de que se pretende averiguar las ideologías lingüísticas que reflejan en sus escritos y, además, comprobar cuál es el grado de aceptación hacia el colectivo LGTBI. 


\section{Análisis y resultados: ¿qué ideologías lingüísticas se expresan hacia el colectivo LGTBI?}

\subsection{Fernando Lázaro Carreter}

En la única columna que escribió acerca del colectivo LGTBI, Lázaro Carreter cuestiona la formación de la palabra "homosexual" por su prefijo porque "homos" y "homo", en palabras del autor, no significan lo mismo, tal y como refleja en el ejemplo (1):

1) No es infrecuente error, pero impensable en el autor del desmán, sin duda selecto funcionario. Porque la condición de homosexual nada tiene que ver con el homo 'hombre' latino, sino con el griego homos, que significa 'igual': en efecto, a los homosexuales les gustan las personas de igual sexo. (Lázaro Carreter, 03/03/2002)

Pero no solo critica el prefijo "homo" y su significado para "homosexual", sino que además, critica que la palabra "homosexualidad" solo se emplee para hablar de los hombres homosexuales, mientras que para las mujeres se tenga que emplear el término "lesbianismo" (2) y que la "Ley madrileña", en sus documentos oficiales, haya excluido a las mujeres puesto que, al decir homosexuales, homo solo se refiera a mujer (3):

2) Cabe, sin embargo, explicar por qué se piensa que la homosexualidad alude sólo a la de varones, en correlato con lesbianismo. (Lázaro Carreter, 03/03/2002)

3) Es esta la razón, pensamos, de que, además de la perturbación introducida por el homo latino 'hombre', la Ley madrileña haya dado ese traspiés, sacando a las lesbianas del recinto de quienes, en amor, necesitan al mismo sexo. Si ha reservado homosexuales para los varones que lo son, se debe casi seguro a que ese término ha parecido menos connotado que gay, más respetuoso. (Lázaro Carreter, 03/03/2002)

Otra de las palabras cuestionadas por el autor es el uso frecuente que los hablantes hacen de la palabra "gay". Para el autor, la palabra gay es un "neologismo" que significa "el homosexual contento y hasta orgullosos de serlo" (Lázaro Carreter, 03/03/2002). Sin embargo, el columnista no está de acuerdo con ese uso por el siguiente motivo (4):

4) No estamos seguros de que eso ocurra exactamente así en España, pero las compilaciones de léxico gay, que no escasean en Internet, apoyan esa nota lexicográfica. Hasta en textos hórridamente cibertraducidos aparece hombre alegre en lugar de gay. Así que, hablando con cuidado, se prefiere homosexual a esa última palabra, a costa de fundir sus significados. Además, hay homosexuales que, tal vez, no sentirían satisfacción al ser nombrados gays. (Lázaro Carreter, 03/03/2002)

Por último, también se pregunta sobre el nuevo significado que se le ha proporcionado a la palabra "orientar" para referirse a las identidades sexuales de hombres y mujeres, que lo califica de anglicismo, como se puede observar en (5):

5) Se trata del desarrollo impetuoso que, día a día, va adquiriendo el vocablo género para acoger tanto al varón como a la mujer, incluidas sus distintas orientaciones sexuales. Y acabo de emplear un anglicismo que se está colando en el idioma sin ninguna resistencia; orientar es 'dirigir o encaminar', y la mujer y el hombre no nacen orientados, sino poseedores de una determinada condición, índole o naturaleza: 
cualquiera de estas palabras u otras semejantes hubieran debido elegir quienes, para traducir, macarronizan. (Lázaro Carreter, 03/03/2002)

\section{2. Álex Grijelmo}

Grijelmo, a raíz de un suceso relacionado con el colectivo LGTBI en Estados Unidos, ha observado un error que cometen los medios de comunicación a la hora de escribir el plural de "gay" (6). Por otra parte, en el ejemplo (7) explica el origen de la palabra "gay" y los distintos significados que se les han asignado tanto en francés como en inglés, así como su equivalente en español "gayo", que, según el columnista, fue registrado por Corominas y Pascual sobre el 1400, y que no hacía aún referencia a una persona homosexual. Posteriormente, en cuanto al ámbito del teatro, Grijelmo relata que, antiguamente, como no se permitían a las mujeres representar obras teatrales, los hombres representaban los personajes femeninos; por lo tanto, a raíz de esas situaciones, se empezó a asociar con la "connotación de homosexual" (Grijelmo, 19/06/2016). No obstante, dicha alternativa no tuvo tanto éxito, que, al final, se tuvo que quedar el extranjerismo "gay" (8):

6) La matanza perpetrada en Orlando ha aumentado la circulación de la palabra "gay" en estos días, y por esa lamentable razón se ha podido observar con intensidad el uso de tal término en los medios: La prensa lo muestra sin cursiva y con el plural españolizado: gais. (Grijelmo, 19/06/2016)

7) Por tanto, los términos "gayo" y "gaya" funcionaron en nuestro idioma como espejo de las evoluciones que en inglés y francés afectaron a "gay" y "gai", excepto en lo que se refiere a la homosexualidad. (Grijelmo, 19/06/2016)

8) El poco uso de esa alternativa en castellano dificultó que se le añadiese la nueva acepción de su palabra hermana; y el español periodístico adoptó "gay" desde el inglés, para dejar en segundo plano "homosexual". (Grijelmo, 19/06/2016)

La segunda palabra que cuestiona es la de "mariconez", palabra que viene de maricón y aparece en la letra de una canción del grupo Mecano, y que ha sido criticada por una de las concursantes del programa Operación Triunfo. Para Grijelmo, palabras como esta solo adquieren un determinado significado según el contexto en el que se encuentren (9), y el problema que tiene la mayor parte de la población es que entienden algunas palabras en el sentido literal, cuando lo que realmente deben hacer es entenderlas en el contexto en el que se encuentran, tal y como describe en (10), (11) y (12):

9) Las palabras sólo adquieren su verdadero sentido cuando las activa un contexto. (Grijelmo, 21/10/2018)

10) Uno de los problemas que padecen actualmente quienes escriben libros, artículos o canciones tiene que ver con la incapacidad de una parte del público de percibir mensajes que trasciendan lo literal. Los sentidos figurados y las alteraciones por el uso parecen estar desapareciendo de las herramientas de la comunicación. (Grijelmo, 21/10/2018)

11) Una vez más, se veía en el término literal una mala intención, en este caso homófoba, que sin duda no se dio en la voluntad del autor. Sabemos de sobra que locuciones como "es un hijoputa" o "menudo cabronazo", incluso "vaya mariconcete", adquieren un valor figurado que se escapa de su tenor original. También un adjetivo 
como "sudaca" puede ser despectivo... o cariñoso en grado sumo. (Grijelmo, 21/10/2018)

12) Por tanto, no debemos mirar los significantes, a veces caprichosos, sino el significado y el sentido de lo que se quiere decir. Conviene descodificar en cada caso el mensaje para interpretar las palabras en su contexto, en su ambiente, y en relación con los sentimientos conocidos de quien se expresa. De ese modo se comprendería que no se mostraba homofobia alguna en la canción de Mecano. (Grijelmo, 21/10/2018)

Otras dos palabras que Grijelmo critica en el siguiente artículo del corpus tienen que ver con "homofobia" y "LGTBIfobia", la primera para designar la discriminación hacia los gais y la segunda para referirse a la discriminación hacia todas las orientaciones sexuales dentro del colectivo. En primer lugar, Grijelmo, ante su rechazo al uso de homofobia por los "defectillos" que presenta, propone una alternativa, que finalmente descarta por no ser "muy periodística" (13). Lo mismo ocurre con LGTBIfobia (14), que la considera innecesaria, y, en función de la formación de otros términos para designar discriminaciones como "transfobia", propone una palabra alternativa y que suena mejor para la lengua española, como es "homotransfobia" (15):

13) Desde una mirada purista, la palabra mostraba defectillos. Si analizamos sus cromosomas, no hallaremos ahí el significado "aversión a los homosexuales" sino "aversión a lo igual" (homo-fobia). Pero la alternativa homosexualesfobia no parecía muy periodística; y también jugaba a favor de la propuesta que contásemos con antecedentes como "telenovela" (y no televisionnovela) o "cinéfilo" (en vez de cinematográfilo). (Grijelmo, 26/03/2017)

14) Esto nos conduce a un tercer vocablo en la serie: "LGTBfobia", un híbrido de siglas y elemento compositivo que empieza a prosperar con el fin de referirse a la aversión contra lesbianas, gais, transexuales y bisexuales. Pero ¿es necesario ese revoltijo de letras grandes y pequeñas? Creemos que no. (Grijelmo, 26/03/2017)

15) Y como la aversión a los transexuales se designa con la mencionada "transfobia", eso nos permitiría adoptar un término que puede reunir a todas esas colectividades y superar al citado engendro de mayúsculas y minúsculas gracias a su mejor morfología y fonología: "homotransfobia": sólo cinco sílabas, frente a los siete golpes de voz en "LGTBfobia". (Grijelmo, 26/03/2017)

Por lo tanto, Grijelmo defiende que se debe "combatir el odio a homosexuales y transexuales con palabras que se dirijan contra los intolerantes, pero sin que éstas produzcan a su vez ninguna aversión que las debilite para la denuncia" (Grijelmo, 26/03/2017). Por último, sobre el término "matrimonio", Grijelmo defiende que un matrimonio de hombres "no puede incluir maternidad alguna", pero, si se trata de mujeres, entonces ahí habría que hacer una modificación léxica (16):

16) En efecto, un matrimonio de varones no puede incluir maternidad alguna, sino solamente paternidades. En eso estamos de acuerdo. Sin embargo, un matrimonio de mujeres que adoptara un hijo rebasaría incluso los requisitos de la palabra, pues éste tendría dos madres por falta de una. Sería incluso un bimatrimonio, y así compensaría de sobra lo anterior. (Grijelmo, 09/11/2014) 


\subsection{Amando de Miguel}

Al igual que Grijelmo, Amando de Miguel prefiere utilizar la forma españolizada "gayo" o "gaya", en lugar de la forma inglesa "gay", que lo califica como "una de las tantas modas que copiamos de los Estados Unidos" (De Miguel, 08/07/2020). En cuanto a las siglas del colectivo LGTBI, De Miguel no está de acuerdo con quienes conforman el colectivo y deja fuera a otras personas con otras condiciones, como se ve en (17), (18) y (19):

17) Deja fuera a otras formas de organización de la compañía sexual (que es de lo que se trata), como los célibes, los asexuales, los polígamos (a su vez, poligínocos y poliándricos) y los incestuosos. Así que las siglas auténticas deberían ser LGTBHCAPI. Excluyo a los zoófilos, pero no creo que se sientan muy discriminados, aunque, si se empeñan, también les cedemos una plaza en el colectivo. Se trata de un conglomerado abierto con un punto de exhibicionismo. (De Miguel, 08/07/2020)

18) Tendría que prodigarse más la bandera gaya con tal de que incluyera todas las siglas dichas para que no hubiera discriminaciones. No solo deben contar los símbolos. Más efectiva debería ser la norma de que en la continua provisión de cargos políticos y altos puestos funcionariales se reservara siempre una cuota para el colectivo LGTBHCAPI. (De Miguel, 08/07/2020)

19) La única crítica que podría hacérsele es que se comporta de una manera exclusivista o discriminatoria al no aceptar otras categorías, como los incestuosos, los promiscuos y los zoófilos. (23/06/2017)

En esta última, se debe a la noticia que había leído de que la Junta de Andalucía quería utilizar el término "persona guardadora" en los documentos oficiales, por ser más incluyente que los términos "padre" y "madre". En los siguientes ejemplos, el columnista no acepta ninguna de las sugerencias que le hacen sus lectores puesto que estos quieren que el escritor evite términos peyorativos para el colectivo LGTBI, como se pueden apreciar en los ejemplos (20), (21), (22) y (23):

20) Doña Amaya se refiere a lo "políticamente correcto" para indicar el rechazo de palabras como maricón, tortillera o idiota. El idiota, dice doña Amaya, se sustituye cortésmente por "retrasado mental severo". (De Miguel, 12/09/2005)

21) Lo políticamente correcto es el equivalente del lenguaje ñoño para las malas palabras -que dicen en Argentina- o los tacos o palabrotas, que decimos en España. (De Miguel, 12/09/2005)

22) Pablo Cabeza opina que, entre personas decentes, no debe utilizarse la palabra maricón. Le parece mejor homosexual, aunque tiene el inconveniente de que se fija más en lo genital que en lo sentimental. Quizá gay pueda resultar. No estoy de acuerdo, pero me parece que está bien razonado. (De Miguel, 12/09/2005)

23) Me pide que utilice términos que no causen escándalo y que sean bien recibidos, como gay o lesbiana. Pero iy si yo digo que no me gustan; que me parecen cursis y que apestan a "corrección política"? El mejor término, el más elegante, sería manflorita. Así está en el diccionario. Es una corrupción popular de "hermafrodita", pero sobre corrupciones no vamos a discutir por un quítame allá esas pajas. (De Miguel, 13/09/2005) 
Ante la negativa a usar términos más apropiados, el autor defiende el uso de términos como "maricón" o "tortillera", y alega que no ve ningún problema en hacer uso de ellos puesto que los hablantes lo utilizan en el lenguaje común (24), aunque homosexual y lesbiana los ve "cursis" y el de lesbiana lo ve "impreciso". En el caso de "maricón", este es un "acierto" por la composición de la palabra, como se observa en (25) y (26), y que el hecho de que él quiera usar esa palabra es que quien realmente le da connotaciones negativas al lenguaje son los hablantes (27):

24) En el lenguaje corriente casi todos decimos maricón o tortillera, y no homosexual o lesbiana. Los dos últimos términos (y no digamos gays) son un tanto cursis. El de lesbiana resulta particularmente impreciso. ¿Todas las mujeres de la isla de Lesbos son tortilleras? ¿Lo eran en el pasado? Lo de homosexual se aplica solo a los varones (pero que en parte se consideran mujeres o con modos femeniles). (De Miguel, $12 / 08 / 2005)$

25) Pero en ese caso será mejor que no alardeen de su orientación sexual, no sean exhibicionistas por el atuendo o el lenguaje. Mala cosa cuando hay que salir en procesión burlesca demostrando el "orgullo gay". La palabra maricón me parece un acierto. El prefijo mari alude a los rasgos femeniles que distinguen a los homosexuales. El sufijo ón recuerda a varón o quizá lo exagerado. Es evidente la ambigüedad, pero es la que practican los homosexuales declarados. (De Miguel, $12 / 08 / 2005)$

26) Vamos que lo de maricón me parece una palabra más precisa y expresiva. Si alguien se ofende, peor para él o para ella. Nunca llamaría mongolito a un niño mongólico o con síndrome de Down. Lo de "mongólico" es palabra muy apta y en modo alguno es despreciativa. (De Miguel, 12/08/2005)

27) Don Eduardo no está de acuerdo con mi resistencia a emplear la voz gay para sustituir la de "maricón", tan denigrante. Mi opinión es que el carácter denigrante lo pone el pueblo, no yo. Por otra parte, aceptaría gay si se dijera gayo o, en todo caso, guey. Desde luego, no es algo que me quite el sueño. (De Miguel, 05/10/2005)

Si Grijelmo decía que el plural de "gay" se escribe con la terminación "-is", De Miguel escribe que se escribe con "y", es decir "gays", y añade, además, que usar homosexual es sexista porque solo se refiere a hombres. Por lo tanto, es mejor usar "gayos" y "gayas" para referirse a los dos sexos (28):

28) Paco Carvajal me pregunta: “¿Cuál es el plural de gay?”. Muy sencillo: gays. Resulta raro, ya me doy cuenta. Para empezar, es extraño que gay se refiera a un varón homosexual y no a una mujer homosexual. ¿No es un tanto machista esa atribución? Lo mejor sería aceptar la voz gayo o gaya, que así se aplicaría a los tres sexos (varones, mujeres y transexuales).(De Miguel, 29/08/2005)

En tres de sus columnas recopiladas, De Miguel critica el neologismo "heterófobas" que se coreó en una manifestación del Orgullo LGTBI en Madrid, porque no existe (29); utiliza el humor para hablar del apellido del activista y político del PSOE Pedro Zerolo (30) por su origen y la relación que guarda con el colectivo, y, además, califica la "homofobia" (palabra que sí que está recogida en el Diccionario) de ser un "neologismo" y un "disparate léxico", por la ambigüedad que genera (31):

29) En la reciente manifestación de Madrid a favor de la familia no se veían u oían alusiones "homófobas". En cambio, en la manifestación del orgullo gay, celebrada a 
los pocos días, sí se veían y se oían alusiones "heterófobas". Esa palabra no existe y podría significar "temor a los que son distintos", en ese caso por parte de los gayos. Obsérvese que los homosexuales continuamente alardean de que lo son, a través del lenguaje, los gestos, la vestimenta. En cambio, los heterosexuales no suelen alardear mucho de su condición, fuera de algunos macarrillas. Da la impresión de que los homosexuales hodiernos no solo han salido del armario sino que lo llevan a cuestas. (De Miguel, 28/07/2005)

30) Por otro lado, me encanta un gayo que se acoge al nombre de guerra de Zero Kelvin. Como es sabido, la voz zero, en la jerga gaya, significa "culo", "ano", en su sentido sexual. ¿No es eso un alarde? ¿No es fantástico que el líder de los gayos sea un tal Zerolo? (De Miguel, 23/09/2005)

31) Por cierto, un disparate léxico es el del neologismo homofobia (odio a los y las homosexuales). En rigor, con las dos palabras griegas, homofobia tendría que ser "odio a los semejantes". La confusión es que la partícula griega omo quiere decir "semejante"; en latín, homo significa "persona humana". (De Miguel, 09/07/2021)

\subsection{Elena Álvarez Mellado}

Las dos columnas de Elena Álvarez Mellado se centran en dos cuestiones: la aparición de la terminación -e como tercer género y la reapropriación de insultos por parte del colectivo LGTBI. Por una parte, la columnista defiende en (32) que el uso de la terminación -e supone un acto reivindicativo para aquellas personas que no se sienten identificadas con la dicotomía masculino-femenino. Hubo un intento de proponer el uso de la -x y la @, pero, debido a las dificultades de lectura que suponían, se prefirió optar por la -e (33):

32) La propuesta es que este tercer género sirva para denominar a las personas de género no binario (personas que no son hombre ni mujer) y ya de paso ejerza además de neutro genérico (la función que tradicionalmente ha asumido el masculino, como cuando decimos "nosotros" para referirnos a un grupo mixto). (Álvarez Mellado, 27/06/2017)

33) La propuesta de construir un género neutro en -e soluciona muchos de los escollos que las anteriores propuestas dejaban sin resolver: fácil de pronunciar, morfológicamente claro, lingüísticamente económico, socialmente inclusivo. (Álvarez Mellado, 27/06/2017)

Sobre el uso de la -e, Navarro-Carrascosa (2021) afirma que, a pesar de haber sido regularizado el género gramatical no binario en países como Suecia y Holanda, en España, "la normativa académica no reconoce un género que se salga de la dicotomía masculino-femenino" (Navarro-Carrascosa, 2021, p.180). La forma -i no se utiliza para "hacer un género inclusivo", sino que se utiliza para "formar actos de habla afiliativos" en situaciones irónicas o cómicas, mientras que la forma -e se utiliza para "formar un género gramatical inclusivo" para incluir a los dos géneros y eliminar el masculino génerico, "e incluir en la lengua a personas que se catalogan como no binarias y no se sienten representadas por los géneros gramaticales masculino y femenino" (Navarro-Carrascosa, 2021, p.199). Por otra parte, palabras como "puta, bollera o maricón" son calificativos con los que se ha pretendido atacar al colectivo, pero que muchas personas del colectivo LGTBI se han apropiado de estos insultos como un acto reivindicativo para dejar en evidencia al que lanza la ofensa, como se ve en (34) y (35): 
34) Puta, bollera o maricón son otros casos recientes de palabras acuñadas y usadas en su origen con intención peyorativa que han sido reclamadas y asumidas con orgullo por el propio colectivo insultado. (Álvarez Mellado, 27/03/2017)

35) Al hacer bandera de la ofensa, no solo se desactiva el insulto y se desmonta el ataque, sino que además se le da la vuelta a la tortilla poniendo en evidencia a quien intentaba herir. (Álvarez Mellado, 27/03/2017)

La última palabra que menciona en sus columnas tiene que ver con la palabra queer, que en un principio tenía un significado peyorativo (raro, extraño), pero con el paso del tiempo y el uso continuado en su forma inglesa en la lengua española ha hecho que los hablantes piensen que se trata de "un tecnicismo académico" y se olviden de la historia real que hay detrás de ese concepto $(36,37)$. Es por eso que la autora defiende la importancia de conocer el origen de las palabras para poder seguir reivindicando (38):

36) Si no conocemos la historia de la palabra, en español queer nos puede parecer un tecnicismo académico propio de manifiestos activistas o disertaciones filosóficas. Pero bajo su aspecto inofensivo, la palabra queer también esconde la historia de un insulto reapropiado. (Álvarez Mellado, 27/03/2017)

37) Feminismo y queer son dos palabras que, a pesar de gozar de buena salud lingüística en español, han perdido parte de su memoria histórica por el camino: en el caso de feminismo, por amnesia colectiva; en el caso de queer, porque al traernos el extranjerismo, necesariamente nos quedamos sin la tradición histórica que arrastra en su lengua original. (Álvarez Mellado, 27/03/2017)

38) Conocer y recordar el origen de estas palabras es una forma de reivindicar y mantener vivas las luchas políticas que nos han traído hasta aquí. (Álvarez Mellado, 27/03/2017)

\subsection{Lola Pons Rodríguez}

Pons Rodríguez, en uno de sus artículos, critica las diferencias de género que existen entre los hombres homosexuales y las mujeres homosexuales en cuanto a adjetivos calificativos. Los únicos que menciona para el caso de las mujeres son los de "machorra" o "marimacho" (39). Un tercer adjetivo calificativo fue el de "varona", término que estaba dirigido a aquellas mujeres heroínas en las guerras (40). No obstante, ahora que el lesbianismo empezó a visibilizarse, los adjetivos machorra y marimacho dejaron de tener importancia (41):

39) Con todo, había una obvia descompensación en ellos: se usaba un amplísimo número de adjetivos para la homosexualidad masculina, pero en cambio la homosexualidad femenina en español se señalaba históricamente con apenas dos términos: marimacho y machorra. (Pons, 04/07/2018)

40) En ambos casos, marimacho y machorra tenían un valor despectivo en su aplicación a mujeres. En cambio, no tuvo tal sentido ofensivo un tercer adjetivo usado en español para designar a lo que se entendía como mujer varonil: varona. La palabra varona se utilizaba para traducir al latín 'virago' y se aplicaba para calificar a heroínas o diosas de la antigüedad que fueron célebres en guerras, batallas o en menesteres que se tenían por típicos de los hombres. (Pons, 04/07/2018) 
41) La llave que abrió el armario no fue lingüística, pero cuando la homosexualidad femenina salió masivamente del armario, 'marimacho' y 'machorra' empezaron, afortunadamente, a dejar de ser las palabras claves. (Pons, 04/07/2018)

En el segundo artículo recopilado en el corpus de Pons Rodríguez (14/08/2017), la autora escribe que, ante ciertos anglicismos, como es el caso de "WorldPride", los hablantes no utilizan la traducción "Orgullo Mundial", sino que más bien españolizan la pronunciación de la palabra inglesa, un fenómeno que puede estar relacionado con el nivel nulo de idiomas que hay en algunos sectores de la población en España (42). Por último, Pons Rodríguez se pregunta por la existencia de las llamadas "palabras trans", es decir, aquellas palabras que, en un principio eran masculinas, pero, con el paso del tiempo, se convirtieron en femeninas, y viceversa, lo que le lleva a reflexionar que el género no es más que una "opción" (43):

42) Pasada ya con éxito la celebración del WorldPride 2017 en Madrid, lo traemos a la actualidad para hablar de lengua española. En primer lugar, para preguntarnos: ¿por qué no lo hemos llamado Orgullo Mundial? Hemos oído cosas del tipo "guolpride", "goldpraid" y similares. En la patria de la "relaxing cup de café con leche", la opción por hispanizar anglicismos debería ser una cuestión de aceptación de nuestra inutilidad con los idiomas y no tanto de preservación del honor del español frente al inglés. (Pons, 14/08/2017)

43) El español nos proporciona muestras de todo tipo de trasvases, ampliaciones y cambios de esta clase. De hecho, en esto del género vemos que en las palabras casi nada es para siempre y que en ellas, como en las personas, lo del género es más una opción que una obligación de naturaleza o nacimiento (lo que, para el caso de la lengua, viene a ser la etimología). (Pons, 14/08/2017)

\subsection{Francisco Ríos Álvarez}

En sus columnas sobre la lengua, Ríos reflexiona que, para hablar de la discriminación de todas las personas y de todas las orientaciones LGTBI, no existe un sustantivo adecuado en la lengua española (44). No obstante, aunque la mayoría de los hablantes empleen la palabra "LGTBIfobia" para hablar de todas esas discriminaciones, el columnista muestra sus dudas sobre la corrección de su escritura (45) y no ve normal que se mezclen letras mayúsculas con minúsculas (46), porque implicaría aprenderse el orden de las siglas (47):

44) Existen palabras para designar la aversión a los gais (homofobia), a las lesbianas (homofobia y lesbofobia), a los transexuales (transfobia) y a los bisexuales (bifobia), aunque solo homofobia aparece en el Diccionario. Y ha surgido el problema de hallar un sustantivo que dé nombre al rechazo a todas esas identidades y tendencias. (Ríos Álvarez, 14/04/2017)

45) Lo que no está claro es cómo se escribe cuando sigue a una sigla: ¿LGTB fobia, LGTB-fobia o LGTBfobia? Hay quien cree que esta última, LGTBfobia, es la grafía más adecuada, sin guion por estar el elemento compositivo en posición final. (Ríos Álvarez, 14/04/2017)

46) Pero no es normal una palabra con dos o más mayúsculas seguidas de minúsculas. Y un elemento compositivo cuya sílaba inicial formase una nueva sílaba con la última mayúscula complicaría el problema. LGTBlogía, por ejemplo, se leería [elegeteblogía], con lo que se pierde la noción de la sigla base, que, sin embargo, se conserva en LGTB-logía. (Ríos Álvarez, 14/04/2017) 
47) El problema es su longitud y la dificultad de articularlo espontáneamente, pues exige repasar mentalmente el orden de las letras de la sigla. Si a ello se le añade que este acortamiento tiene variantes, la cuesta se empina aún más. (Ríos Álvarez, $14 / 04 / 2017)$

En segundo lugar, Ríos expresa que es difícil encontrar adjetivos que se atribuyan a los homosexuales y que no contengan una carga peyorativa, e incluso hay hablantes que, ante la longitud de las palabras "homosexual" y "heterosexual", prefieren abreviar a "homo" y "hetero", a pesar de que muchos críticos no están de acuerdo (48). Sin embargo, añade que, si se va a incluir en la lengua española, se debe hacer "sin diacríticos" y con el plural "gais" (49). Por último, sobre la palabra "maricón", el autor afirma que esta adquiere una connotación de odio dependiendo del contexto (50):

48) Es difícil encontrar nombres que designen a los homosexuales y que para ellos sean aceptables, pues casi todos son peyorativos. En ese panorama, donde la voz homosexual parece excesivamente formal y a algunos se les hace extensa -son los que usan abreviamientos del estilo de homo y hetero- , surge, importada del inglés, una muy breve y no ofensiva: gay. Su triunfo en el uso ha sido rotundo, pese a las resistencias de quienes consideran innecesario el anglicismo. (Ríos Álvarez, 08/07/2002)

49) Parece difícil que vayan a dar marcha atrás quienes emplean del anglicismo, y menos cuando ya ha recibido las bendiciones de la autoridad. Si se acepta esa realidad, debe escribirse gay sin diacríticos. Y en plural ya no son gays, sino gais. (Ríos Álvarez, 08/07/2002)

50) Maricón no se dirige solo a homosexuales cuando se usa como improperio -para lo cual no hace falta odiar a los gais, sino que basta con ser malhablado-, caso en el que podría encajar el «O paras de grabar o te mato, maricón». Pero en los repetidos gritos de «maricón de mierda» ya cabe ver injurias reservadas a los gais, lo que podría ser un indicio de homofobia en quienes atacaron con tanta saña a la víctima. Aunque ese extremo habrán de determinarlo los jueces. (Ríos Álvarez, 17/07/2021)

\section{Resultados y conclusión}

Como ya se mencionó en la introducción, el objetivo principal de este trabajo es averiguar qué ideologías lingüísticas presentan Fernándo Lázaro Carreter, Álex Grijelmo, Lola Pons, Elena Álvarez Mellado, Amando de Miguel y Francisco Ríos Álvarez en sus columnas sobre la temática LGTBI, y, en función de ello, comprobar hasta qué punto esto supone un apoyo a las reivindicaciones del colectivo para utilizar un lenguaje no discriminatorio o si mantienen su purismo ante las novedades lingüísticas. Las palabras más analizadas en las columnas han sido homofobia, homosexual, gay, LGTBIfobia o maricón, presentes en las columnas de Grijelmo, Pons, Ríos y De Miguel, aunque también Álvarez trata otras cuestiones como la terminación -e o la apropiación de los insultos o incluso esos autores mencionados hablan de otras cuestiones lingüísticas, como se ha visto en el anterior apartado.

Sobre la palabra homofobia y LGTBIfobia, Grijelmo, de Miguel y Ríos no están de acuerdo con su uso: en el caso de homofobia, por su ambigüedad (31) o porque solo recoge la discriminación de una orientación y no de los otros (44), y, en el caso de LGTBIfobia, porque no se puede mezclar siglas en mayúsculas con minúsculas (46). Por su parte, Grijelmo intenta proponer una alternativa a 
homofobia, pero acaba siendo rechazada, como se ve en el ejemplo (13). En cuanto a las palabras homosexual y gay, Lázaro Carreter, Ríos y Pons Rodríguez tratan diferentes cuestiones: para Lázaro Carreter, homosexual es la palabra que prefiere utilizar antes que gay, puesto que esta última tiene una connotación que no se corresponde a la realidad del colectivo (4). Pons Rodríguez habla desde el punto de vista del género, puesto que alega que homosexual tiene más adjetivos para referirse a hombres que a mujeres, como se refleja en el ejemplo (39), y que, a día de hoy, hay más adjetivos con connotación peyorativa en el caso de las mujeres lesbianas. Por otra parte, Ríos, tal y como ha reflejado en (48), escribe que apenas hay adjetivos no peyorativos para los homosexuales, que deja en evidencia la existente homofobia en la sociedad española. En el caso de de Miguel y Grijelmo, ambos autores coinciden en que prefieren utilizar la forma españolizada de "gayo" o "gaya" (7) y (28).

De Miguel, Grijelmo y Ríos hablan sobre la palabra "maricón" de la siguiente manera: tanto Grijelmo como Ríos están de acuerdo en que maricón puede resultar en odio a los homosexuales o no en función del contexto en el que se encuentran, como se ha ejemplificado en (9), (10), (11), (12) y (50). Por otro lado, de Miguel, como respuesta a sus lectores que le recriminan su forma de dirigirse a los homosexuales, prefiere decir "maricón" porque lo considera "preciso" y "acertado" por los rasgos femeninos que estos presentan, como se ha visto en los ejemplos (24), (25) y (26). Sobre este aspecto, y retomando la lingüística queer, NavarroCarrascosa (2021) divide los apelativos en dos tipos: los apelativos externos al colectivo, que son los que utilizan "emisores de fuera del colectivo" que implican "actos amenazantes", y los apelativos internos del colectivo, que son los que utilizan emisores dentro del colectivo (Navarro-Carrascosa, 2021, pp. 358-359). De este último, destacan aquellos apelativos que utilizan "agentes externos al colectivo para atacar a sus miembros" y que han sido apropiados por el propio colectivo, dándoles otra "carga semántica" (Navarro-Carrascosa, 2021, p. 359). En el caso de las Columnas sobre la lengua, los columnistas han reflejado estos fénomenos para ilustrar a sus lectores cómo la palabra "maricón" ha adquirido diferentes cargas semánticas tanto por hablantes de fuera del colectivo como los miembros del colectivo. Por otra parte, Álvarez Mellado y Pons Rodríguez se centran en cuestiones de la evolución del lenguaje como acto de reivindicación para incluir un tercer género en la dualidad binaria masculino-femenino, como la terminación -e (32) y (33) o la inclusión de "palabras trans" (43).

A modo de conclusión para este trabajo, se puede decir que cinco de los seis autores del corpus se muestran favorables a evitar aquellos adjetivos discriminatorios contra el colectivo LGTBI, aunque algunos todavía siguen manteniendo su purismo lingüístico cuando se trata de determinados términos como ha sido el caso de gay, por tratarse de un extranjerismo, y prefieren utilizar palabras que no amenacen el estatus de la lengua española.

\section{Referencias}

1. Barrett, R. (2002). Is Queer Theory Important for Sociolinguistic Theory? In Kibler, K., Podesva, R., Roberts, S. y Wong, A (Eds.), Language and Sexuality: contesting Meaning in Theory and Practice (pp. 26-43). Stanford: Center for the Study of Language and Information.

2. Boellstorff, T.; y Leap, W. L. (2004). Introduction: Globalization and "New" 
Articulations of Same-Sex Desires. In Leap, W. y Boellstorff, T (Eds.) Speaking in Queer Tongues: Globalization and Gay Language (pp. 1-21). Urbana and Chicago: Illinois University Press.

3. Borba, R. (2015). Linguística Queer: una perspectiva pós-identitária para os estudos da linguagem. Revista Entrelinhas, 9 (1), pp. 91-107.

4. Bucholtz, M. y Hall, K. (2004). Theorizing identity in language and sexuality research. Language in society, 33, pp. 469-515. https://doi.org/10.1017/S0047404504334020

5. Butler, J. (2006). Deshacer el género. Barcelona: Paidos Studio 167.

6. Carratalá, A. y Herrero, B. (2019). La regulación contra el discurso de odio hacia el colectivo LGTBI en los medios: análisis comparado de diez leyes autonómicas. RAEIC, Revista de la Asociación Española de Investigación de la Comunicación 6 (12), pp. 58-80. https://doi.org/10.24137/raeic.6.12.3

7. Cazorla, A. (2019). La identidad gay en la columna El Bufón de Elvira Lindo. Revista Internacional de Culturas y Literaturas, 22, pp. 37-51.

8. Córdova, H. (2019). Hacia un breve glosario queer. algunas nociones acerca del genero, la sexualidad y la teoría queer. Análisis, 52 (96), 95-121. https://doi.org/10.15332/21459169/5326

9. de Lauretis, T (2015). Genero y teoría queer. Mora, 21, 107-118.

10. del Valle, J. y Meirinho, V. (2016). Ideologías lingüísticas. CUNY Academic Works, pp. 622-631

11. Frühbeck, C. (2017). En busca del genio: la labor purista de Grijelmo. Tonos digital: Revista de estudios filológicos, 32, pp. 1-29.

12. Guerrero Salazar, S. (2019). Las CSL en la prensa española de los 80. Mujeres y feminismo. En Marimón Llorca, C. (Ed.), El columnismo lingüístico en la prensa española desde 1940: Análisis multidimensional y caracterización genérica (pp. 185-208). Madrid: Arco/Libros.

13. Guijarro-Ojeda, J. R. y Ruiz-Cecilia, R. (2019). La representación de personas LGTBI+ en prensa española conservadora y progresista. Convergencia. Revista de Ciencias Sociales, 80, pp. 1-25. https://doi.org/10.29101/crcs.v26i80.10783

14. Leap, W. L. (2003). Language and Gendered Modernity. In Holmes, J. y Meyerhoff, M. (Eds.), The Handbook of Language and Gender (pp. 401-422), Malden, MA: Blackwell Publishing. https://doi.org/10.1002/9780470756942.ch17

15. Livia, A. y Hall, K. (1997). Queerly Phrased. Language, Gender and Sexuality. New York: Oxford University Press.

16. Marín-Calderón, N. (2020). Encuentros entre psicoanálisis lacaniano y teoría queer. Sociológica, 35 (100), pp. 81-102.

17. Molina Ríos, J. A. (2019). Estudios del lenguaje desde una perspectiva glotopolítica. Signo y Pensamiento, 38 (74), pp. 1-9. https://doi.org/10.11144/Javeriana.syp3874.elpg

18. Moreno Sánchez, J. (2018). Análisis (crítico) del discurso legislativo en materia de educación en el Estado español desde una perspectiva queer. Tesis de doctorado, Universidad de Alicante. Alicante: Repositorio Institucional de la Universidad de Alicante.

19. Motschenbacher, H. y Stegu, M. (2013). Queer Linguistic approaches to discourse Discourse \& Society, 24 (5), pp. 519-535. https://doi.org/10.1177/0957926513486069

20. Navarro-Carrascosa, C. (2019). Nuevas terminaciones para nuevas realidades: performatividad, afiliacion y atenuacion en la comunidad de habla LGTBI. ELUA, 35, pp. 179-201. https://doi.org/10.14198/ELUA2021.35.9

21. Navarro-Carrascosa, C. (2020a). Caracterización del discurso de la comunidad de habla LGTBI. Una aproximación a la lingüística queer hispánica. Revista de Investigación Lingüistica, 23, pp. 353-375. https://doi.org/10.6018/ril.393531

22. Navarro-Carrascosa, C. (2020b). Análisis pragmalingüístico de las formas nominales de tratamiento en la comunidad de habla LGTBI. Tesis de doctorado, Universidad de Valencia. Valencia: Repositori d'Objectes Digitals per a l'Enseyament la Recerca i la Cultura.

23. Navarro-Carrascosa, C. (2021). Nuevas terminaciones para nuevas realidades: 
performatividad, afiliación y atenuación en la comunidad de habla LGTBI. ELUA, 35: pp. 179-201.

24. Oliveira, R. (2019). Trans en los media: Un estudio comparativo piloto del tratamiento de la transexualidad en la prensa generalista y los medios de comunicación digitales. Mediatika, 17, pp. 147-168.

25. Oller, M. y Chavero, P. (2016). Ecuador, colectivo LGTBI y medios de comunicación. En Oller Alonso, M. y Tornay-Márquez, Maㅡ C. (Coord.), Comunicación, periodismo y género. Una mirada desde Iberoamérica (pp. 17-77). Sevilla: Egregius Ediciones.

26. Pano Alamán, A. (2019). La ironía y el humor al servicio de la norma ejemplar en los "dardos" de Fernando Lázaro Carreter. En Marimón Llorca, C. y Santamaría Pérez, I. (Eds.), Ideologías sobre la lengua y medios de comunicación escritos. El caso del español (pp. 339-355). Berlín, Peter Lang.

27. Pano Alamán, A. (2020). Marcas polifónicas en las Columnas sobre la lengua en la prensa española. Textos en Proceso, 6 (2), pp. 128-145. https://doi.org/10.17710/tep.2020.6.2.9panoalaman

28. Preciado, P. B. (2002). Manifiesto Contrasexual. Traducción de Julio Díaz y Carolina Meloni. Editorial Anagrama.

29. Preciado, P. B. (2009). Historia de una palabra. Parole de queer, 1, pp. 14-17. http://paroledequeer.blogspot.com/p/beatriz-preciado.html

30. Remysen, W. (2005). La chronique de langage à la lumière de l'experiénce canadiennefrançaise: un essai de définition. En Bérubé, J., Gauvin, K. y Remysen, W. (Eds.), Les Journées de linguistique. Actes du 18e colloque 11-12 mars 2004 (pp. 267-281). Québec: Centre interdisciplinaire de recherches sur les activités langagières.

31. Remysen, W. (2011). L'application du modèle de l'Imaginaire linguistique à des corpus écrits: le cas des chroniques de langage dans la presse québécoise. Langage et société, 135 (1), pp. 47-65. https://doi.org/10.3917/ls.135.0047

32. Rodríguez-Ordóñez, I. (2019). The role of linguistic ideologies in language contact situations. Language and Linguistic Compass, 13 (10), pp. 1-26. https://doi.org/10.1111/lnc3.12351

33. Rojas, D. (2013). Actitudes e ideologías de hispanohablantes en torno a las lenguas indígenas en el Chile del siglo XIX. Lenguas Modernas, 42, pp. 85-98.

34. Sáez, J. (2003). Ensayo homosexual, gay, queer. Revista LEER, 145, pp. 20-23

35. Sánchez Manzanares, C. (2019). La unidad del idioma y otras ideologías lingüísticas en las columnas sobre la lengua de Álex Grijelmo. En Marimón Llorca, C. y Santamaría Pérez, I. (Eds.), Ideologías sobre la lengua y medios de comunicación escritos. El caso del español (pp. 217-234). Berlín, Peter Lang.

36. Santamaría, I. (2019). ¿Purismo o modernidad? Actitudes tradicionales o innovadoras ante los neologismos por préstamo en las columnas sobre la lengua (CSL). En Marimón Llorca, C. y Santamaría Pérez, I. (Eds.), Ideologías sobre la lengua y medios de comunicación escritos. El caso del español (pp. 235-25). Berlín, Peter Lang,

37. Sedgwick, E. K. (1985). Between men. English Literature and Male Homosocial Desire. Nueva York, Columbia University Press. https://doi.org/10.7312/sedg90478

38. Solana, M. (2018). Normatividad, asimilacion y transgresion en Teoria Queer. Revista de Filosofía: Aurora, 30 (51), pp. 776-796. https://doi.org/10.7213/19805934.30.051.AO02

39. Theodoro, H. y Bailén, A. (2019). Tratamiento periodístico de personas LGTBIQ+ refugiadas: estudio de caso sobre Pride Barcelona 2018. Ámbitos. Revista Internacional de Comunicación, 46, pp. 48-65. https://doi.org/10.12795/Ambitos.2019.i46.04

40. Wittig, M. (1992). El pensamiento heterosexual y otros ensayos. Traducción de Javier Sáez y Paco Vidarte. Barcelona: Editorial Egales.

41. Woolard, K. (1992). Language ideology: issues and approaches. Pragmatics, 2 (3), pp. 235-249. https://doi.org/10.1075/prag.2.3.01woo 